\section{E.P. Marques ${ }^{\mathrm{a}}$,} H.F. Marin ${ }^{\mathrm{b}}$, E. Massad ${ }^{\mathrm{c}}$, L. Ohno-Machado ${ }^{\mathrm{d}}$

\author{
a State University of Rio de Janeiro, Brazil \\ ${ }^{b}$ Federal University of Sao Paulo, Brazil \\ ${ }^{c}$ University of Sao Paulo, Brazil \\ dDecision Systems Group, Brigham and \\ Women's Hospital, Health Sciences and \\ Technology Division, Harvard/MIT, USA
}

\section{Introduction}

Brazil is a developing country and its problems are similar to the nations in the same phase of development. Nonofficial statistics show that the literacy rate is still low. The educational system has both private and government activities on all levels, but it is still smaller than the current demand.

Nevertheless, the field of medical informatics has experienced extraordinary growth in the past few years. Increasing awareness of the need for trained personnel has led to the development of several training programs in different continents. As with any new field, highly qualified faculty tends to concentrate in a few centers of excellence. Consequently, establishing formal programs to provide broad training and education is currently an enormous challenge.

Brazilian academic institutions have developed programs to implement

\title{
Research and Education
}

\section{Training in Health Informatics in Brazil}

\begin{abstract}
Technology is transforming not only the practice of healthcare but also professional training and educational models. Developing countries, such as Brazil, are increasingly suffering from a severe shortage of health informatics specialists. Training of professionals in this field is expensive, and there is a limited supply of high-quality teaching resources available. We envision that training in health informatics can be better achieved if cultural and technological barriers are anticipated and the training program is prepared accordingly. We describe our four-year experience of a Brazil/USA training program and discuss lessons learned during its implementation. Eleven onsite courses, one seminar, and two conferences were developed under this unique initiative, which made possible the collaboration among different countries and distinguished leaders in the field of medical informatics. We also described a few identified initiatives to implement health informatics in the curriculum.
\end{abstract}

health informatics content in the curriculum of medical and nursing programs, but they are far from being capable to fulfill the demand in the country.

\section{Brazilian Initiatives in Health Informatics Education}

There are few graduate programs, specially in multidisciplinary areas, such as health informatics. Up to now, no official research funding agency recognizes health informatics as a field of knowledge, so that the project submissions for grants must be characterized as informatics, biology, medical, nursing, mathematical, epidemiology or engineering projects. Therefore just a small amount of funds are directed to support research in the field.

Some of the pioneer initiatives in education and research health informatics are:

- Medical Informatics Discipline -
Sao PauloUniversity. It is the oldest one. The head is Dr. Eduardo Massad, one of the co-authors of this paper. Updated information of the courses can be accessed at netsim.fm.usp.br/dim/

- Health Informatics Department Federal University of Sao Paulo. It is chaired by Dr. Daniel Sigulem. Additional information can be obtained at www.unifesp.br/dis/

- Biomedical Engineering Program - Federal University of Rio de Janeiro. It was the first program in biomedical engineering in Brazil (1970), and is currently dedicated to medical informatics, clinical and medical engineering. Detailed information is available at www. peb.ufrj.br

- Biomedical Informatics Center Campinas University. It was created in 1983. It is a research and a training center. The head of the department is Dr. Renato Sabbatini. Additional information is available at www.nib.unicamp.br 
- Nursing Informatics Center Federal University of São Paulo. It was established in 1990, led by Dr. Heimar Marin, a co-author of this paper. It is the pioneer graduate and undergraduate nursing informatics educational program in Brazil. Detailed information on courses are available at www. unifesp.br/denf/nien

- Medical Informatics Discipline State University of Rio de Janeiro. Dr. Ronaldo Gismondi is the current head of the department. It was created in 1986. Complete information is available at www.lampada. uerj.br

Some other initiatives in health informatics education are more recent, such as:

- Computational and Mathematical Biology Group-Federal University of Rio de Janeiro. It was created in 1994. It is dedicated to medical informatics, biomathematics and bioinformatics. Detailed information is available at www.biomat.org

- Health Informatics Discipline located in a city in Sao Paulo state, Marilia Medical School, created the health informatics discipline in 1998. The program is based on PBL (problem-based learning) approach for undergraduate medical students. The chair of the discipline is Dr. Paulo M. Carvalho Jr. Detailed information is available at www. famema.br/disc/is/

- Medical Informatics Discipline Catholic University of Rio de Janeiro has established the newest program. This university has expertise in informatics training for decades, but just recently has created a 400 hour graduate course in medical informatics. The head is Dr. Eduardo Marques. The first student group will conclude training in 2004. Additional information is available at www.puc-rio.br/ ensinopesq/ccpg/

\section{The Consortium}

AftercarefulconsiderationofBrazilian needs and the award of a training grant from the Fogarty International Center of the National Institutes of Health (USA), we established a bilateral consortium of health informatics faculty and designed a program that could enhance training in Brazil, by augmenting the teaching resources of localfaculty. We based this training program on the experience of the Brazilian faculty and some lessons learnedfrom an existing training program in Boston, which involves faculty from Harvard and its affiliated hospitals, MIT, Boston University, and Tufts University.

The long-term goals of this program, which were established during the grant's application phase, were:

- Establishment of a small scale training program in medical informatics for Brazilian scientists and health professionals that could serve as a test bed for combined onsite and online instruction.

- Development, implementation, and evaluation of distance learning capabilities, involving health informatics courses and seminars at the graduate level.

- Promotion of exchange of ideas and distribution of access to computer-based tools that enable more effective cross-border research, closer monitoring and better delivery of health care (with special emphasis on health promotion and disease prevention) in Brazil, even in geographically remote sites.

- Establishment of a plan for long-term sustainability of this program through collaborations with Brazilian and other international funding agencies.

\section{Material and Methods}

The program started in October 1999. Since then, it has sponsored eleven onsite courses in Brazil, which were subsequently made available on the Internet and CD-ROM, together with regular medical informatics courses taught yearly at Harvard and MIT. It also allowed, by providing financial support, Brazilian faculty and students to participate in several international conferences in the USA and abroad.

The program started, in years 1 and 2 , with activities targeted at faculty from leading universities in southern Brazil, which are better equipped with staff and material resources than universities in other parts of the country. There were short-courses in Brazil, which were taught by a mix of Brazilian and U.S. faculty, as well as support for faculty enrichment via participation in international scientific events. In years 3 and 4 , the training program was responsible for the organization of several scientific meetings in Brazil and continued to promote student and faculty participation in national and international conferences, short-term courses, and workshops.

Our rationale for concentrating most of our efforts and funding to promote events in Brazilian territory was based on several factors. We strongly believe that a program that targets the faculty (or faculty-to-be) in their home country, to enable them to better educate their own students has more chances of longterm success than one that targets a few students and promotes their training abroad. With the limited funding that we had available, we might be able instead to bring one or two individuals for post-docs in U.S. laboratories. These laboratories might not be conducting research that is directly relevant to Brazilian issues. On the other hand, each Brazilian faculty member has the potential to train several students, is already committed to teaching in Brazil, and has already demonstrated a track record of research and teaching in the field. In our program, U.S. faculty interact with Brazilian faculty to deliver 
a curriculum that makes sense for the Brazilian reality. This interaction, via the Internet and live in Brazilian and U.S. territory, helped the identification of specific areas for long-term collaboration and broadened the opportunities for future funding by international and national agencies.

In general, two types of courses were given: on-site courses in Brazil to teach and reinforce health informatics concepts and promote discussion among faculty and graduate students; and online distance-based courses based on material taught in the US at Harvard and MIT. Faculty interaction during the courses and related activities led to the identification of mutual interests. The on-site teaching included several Brazilian collaborators, as well as some U.S. faculty. The lectures were given in Portuguese and English.
The distance-based courses were delivered over the WWW or in the form of CDs.

During the development and implementation of this training program, we tried to reach different regions of Brazil (see Figure 1), delivering courses that were previously given in Sao Paulo or Rio de Janeiro.

The main objectives of the courses were to prepare junior Brazilian faculty to train medical and other health care students, and to train researchers and other health informatics professionals to facilitate the implementation of information technology in the clinical practice. At the end of each course, symposium, workshop, or seminar, anonymous evaluation forms were distributed. The results are summarized below.

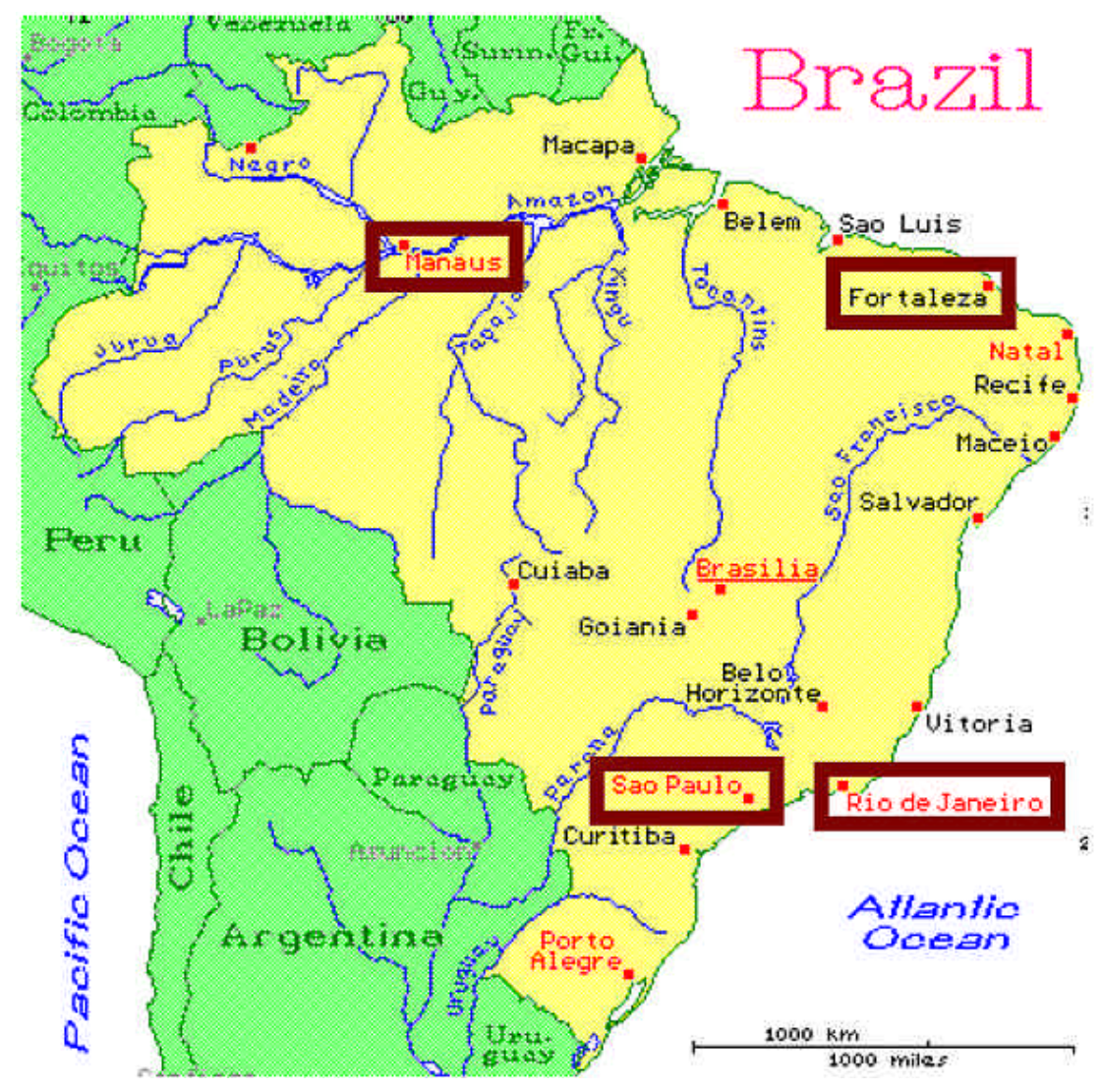

Fig. 1. Geographic distribution of partners institutions and course locations.

\section{Results}

\section{Year $1(1999$ - 2000)}

The first year of the project was based on Sao Paulo and the activities were: (a) a short course in Medical Informatics; (b) a technical visit and a meeting of representatives of the Ministry of Health and Brazilian and American faculty from the training program; (c) participation of Brazilian researchers (direct collaborators) at the AMIA Fall meeting (American Medical Informatics Association) and a Boston workshop in health informatics; (d) support for the Brazilian Congress in Health Informatics.

The first onsite 5-day intensive short course occurred in Sao Paulo, with a team of 5 Brazilian and 5 Americanbased faculty, and had 93 attendees. These individuals came from five different states of Brazil and represented faculty and graduate students in medical informatics from more than ten different academic institutions and industry. In this course, we discussed main introductory concepts in health informatics. In general, the response to the course was very good, with several positive reports. We distributed a questionnaire for assessing subjects' impressions. We received 71 (76\% response rate) questionnaires from participants. Not surprisingly, the majority of the attendees $(60 \%)$ came from the industrialized southeastern part of Brazil. This region in Brazil is well developed and the development and implementation of information technology resources is partially already in place. The topics for the course were chosen by the Brazilian faculty, and included local experience of five different medical informatics centers in Brazil. In general, the participants found the content very useful for further implementation in their professional experience (Table 1). 
Table 1. Overall usefulness. Introduction in Medical Informatics Course I, held in São Paulo, 2000.

\begin{tabular}{|l|c|c|c|c|}
\hline "The course & yes & partially & no & N/A \\
\hline improved my knowledge." & 47 & 21 & 3 & \\
\hline gave me extra resources to teach." & 25 & 14 & 2 & 29 \\
\hline gave me extra resources to work." & 42 & 21 & 5 & 2 \\
\hline gave extra resources to do research." & 36 & 16 & 3 & 16 \\
\hline
\end{tabular}

The course was made available on the WWW and on CDs, and the attendees were encouraged to mirror the site at their servers, as connection to our Boston WWW site proved to be infeasible from Brazil for retrieving audio and motion video.

Following this short course, the US and some Brazilian faculties organized a meeting with the Chair of DATASUS - the institute responsible for the Brazilian Heath Care Database for the Ministry of Health. The objective of this meeting was to identify common interests and to promote local efforts to enhance health informatics in the country by advising local authorities.

In year 2000, the program provided support to the Brazilian Health Informatics Society to organize the Brazilian Congress in Health Informatics, which was attended by 400 participants from several regions of Brazil and South America (Uruguay, Argentina and Chile). Furthermore, a new student award was created. Financial support for attending the American Medical Informatics Association Annual Meeting, November 2000, was provided for the "best student" paper from the Brazilian Congress on Health Informatics, 2000. In addition, 3 Brazilian faculties also received support to participate at the same meeting held in Los Angeles, USA.

\section{Year $2(2000-2001)$}

During the second year of the project, we organized 6 courses in three different cities in the country, sponsored the participation of Brazilian researchers (direct collaborators) at AMIA Fall meeting and MEDINFO 2001 and, (c) support the organization of the BIOMAT conference in Rio de Janeiro.

The 6 courses were delivered in Fortaleza (3), Sao Paulo (1) and Rio de Janeiro (2)

1. Telehealth Symposium - This three-day symposium was held in Fortaleza, the capital city of the Ceará state, in the northern region of Brazil. There were 100 attendees. The main objective was to introduce the basic principles, common practices, and appropriate techniques in Telehealth, as well as give an overview of major systems implemented in developed (telehealth project in State of Arizona, U.S [1]) and developing countries (Brazil and African countries). Brazilian health authorities presented the Ceara State telecommunication program, the Ceara State Public Health and Health Education programs and some pilot projects under development. This symposium was composed of lectures that helped prepare a smaller group of 20 health professionals for the second part of the training, which was a hands-on course, described next.

2. Telemedicine Training Hands-on Course-This two-day small course was held just after the Telehealth Symposium, for a special group of
20 physicians and nurses, selected by the Ceará State Public Health and Health Education programs from Fortaleza and two rural towns (Barbalha and Sobral), which are located circa 160 miles away from the state capital. The health professionals were trained to take pictures of radiological exams, pathological slides and skin lesions, and send them to specialist professionals in Fortaleza, using low priced digital cameras, desktop computers, and low band telephone land lines. A special Java TeleMedMail program (from MIT) was used for this purpose[2].

3. Introduction to Health Informatics Course - This introductory course was held just after the Telehealth Symposium, for a special groups of medical and nursing students. During 36 hours, 48 students had lectures that covered: introduction to health informatics; computeraided instruction; electronic medical records; clinical systems; telecommunications and network infrastructures to support healthcare, homecare, biosignals, and images in medicine; hospital information systems; and decision support systems [1].

4. Medical Decision Support Systems - This advanced course was held in São Paulo, the most industrialized city in Latin America, in May 2001. There were 103 attendees (59 physicians, 23 graduate students, 11 nurses, 8 managers and 2 engineers). These professionals came 
from four different states of Brazil and represented faculty, clinicians, IT specialists, and graduate students in medical informatics from sixteen different academic institutions and companies. Topics such as knowledge-based systems, machine learning, technical methods for protecting privacy in health care data, fuzzy logic applications in health care, and mathematical modeling of disease transmission were covered in this course.

5. Health Informatics Workshop This was a small workshop on basic and intermediate health informatics. The local organizers were the Brazilian Health Informatics Society - Rio de Janeiro chapter. There were around 60 participants including nurses, physicians, engineers and government members that were involved with the Brazilian National Health Card Project.

6. Mathematical and Computational Biology Symposium - This introductory course was held in Rio de Janeiro, from April 2-4, 2001. There were 187 attendees. The main objective was to introduce bioinformatics to graduate students who had recently received undergraduate degrees in Medicine, Nursing, Mathematics, Informatics, Physics, Biology and Chemistry, with emphasis on biomathematical modeling [2]. The main topics were nonlinear dynamics in biological sciences, HIV infection dynamics, patterns of microorganism motility, fuzzy models in epidemiology, computational neuroscience in psychiatrics, biomechanics of connective tissue, molecular evolution of microorganisms, geometric patterns of inflammatory reactions, symmetry in the evolution of the mithocondrial genetic code, "insilico" molecular modeling of proteins, minimal surface geometry in DNA and proteins, threedimensional mathematicalmodeling for arterial system hemodynamics, mathematical models in computerized axial tomography, and pulmonary radiological image segmentation and reconstruction.

The program also provided support to the organization of the BIOMAT, a Mathematical and Computational Biology Symposium that was held in Rio de Janeiro with circa 240 participants from different regions of the country.

\section{Year 3 (2001 -2002)}

During this year, we organized 2 courses in Manaus, which is the largest urban concentration in the state of Amazonas, located in the middle of the jungle, in the northern part of Brazil.

1. Health Informatics and Telehealth Symposium: current perspective This three-day symposium had 124 attendees. The main objective was to introduce basic principles in Health Informatics and Telehealth. The respondents indicated that, for 90 percent, the objectives/expectations were completely achieved. The content of the courses was felt to be immediately applicable to their own environment for 94 percent of the responders. The material used in the courses were considered good/excellent by more than 80 percent of the responders, and the overall organization of the events were rated good/excellent by more than 75 percent of the responders

2. Introduction to Health Informatics Course - This introductory course was held for a special group of medical and nursing graduate and undergraduate students. During 36 hours, 63 students attended lectures that covered: medical knowledge, introduction to health informatics; computer-aided instruction; electronic medical records; clinical systems; telecommunications and network infrastructures to support healthcare, standards in healthcare, literature retrieval, public health systems.

Our activities in this year also included the participation of Brazilian researchers (direct collaborators) at the AMIA (American Medical Informatics Association Annual) Fall Meeting and MIE(Medical Informatics Europe) 2002 congress.

As done previously in 2000, financial support for attending the American Medical Informatics Association Annual Meeting 2002 was provided for the award of the "best student" paper presented at the Brazilian Congress on Health Informatics, 2002.

\section{Year 4 (2002-2003)}

In the final year of this project, we continued to promote the participation of Brazilian researchers (direct collaborators) at AMIA and MIE2003 and supported the organization of four events: the Second Brazilian Symposium on Mathematical and computational Biology, the Biomedical Informatics Seminar held in Rio de Janeiro, the NI $2003-8^{\text {th }}$ International Congress in Nursing Informatics, and the NI2003 post-conference workshop in patient safety.

1. The Second Mathematical and Computational Biology Symposium - This course was held in Rio de Janeiro, from September 22-24, 2002. There were 63 attendees. This symposium was the second edition of the introductory course held the year before. It had the same objectives. The main topics were DNA computing; predatorprey model with non monotonic consumption function; mathematical models for HIV transmission; tumor growth modeling, growth modeling of malignant lymphoma; lymphocyte population diversity and the dynamical stability of immunoglobulin repertoires; shape spaces, metrics and linear 
models for evolutionary rates; microarray images and biological knowledge; neural networks in prediction of biological response; granuloma as a complex system; neural nets in experimental acoustics; the biomathematics of the virus architecture; simulation of a circuit of spinal reflex control; fuzzy method for evaluation of difficult control epilepsy patients; availability of non-heme iron by using the discriminant analysis function; educational activities of the Brazil - USA consortium for health informatics; mathematical modeling of psychodynamics; and health applications with virtual reality technology [3].

2. The Biomedical Informatics Seminar was held in March 2003, with 41 participants and constituted the initial module of the Specialization Course in HealthInformatics provided by the Catholic University of Rio de Janeiro, coordinated by Dr. Eduardo Marques (direct collaborator). This graduate program represents the first initiative to give formal education and training in health informatics in the state of Rio de Janeiro.

3. The project also provided financial support for the NI 2003 Congress $8^{\text {th }}$ International Congress in Nursing Informatics under the theme "e-Health for all: Designing the nursing agenda for the future". NI 2003 congregated over 400 participants from 32 different countries. The Nursing Informatics meetings are hosted by the International Medical Informatics Association Nursing Informatics Special Interest Group (IMIA NI SIG). It was the first time that it was held in a Latin American country and Rio de Janeiro was the elected city.

4. Just after the NI2003 Congress, we organized a post-conference invitational workshop that was also held in Rio de Janeiro. The theme of the NI 2003 post-conference was "Improving patient safety with technology". We invited 40 health care informatics professionals from 15 different countries. The main objective was to produce a book that would be seen as a guideline and an updated source of information in issues related to patient safety and information technology. In addition, the best papers were accepted for publication in the International Journal of Medical Informatics special issue on patient safety.

The material produced by all the courses, conferences, and workshops listed here were made available on the WWW and CDs and are being used by several professionals in the country. As we have not restricted access to registered users to promote the dissemination of the material, it is difficult to ascertain the exact number of beneficiaries of our materials. However, we know anecdotally that is being used by several groups outside the originating group. In our consortium the main users are:

1. Discipline of Evaluation in Medical Informatics - Graduate program, Medical School, Universidade de Sao Paulo, 10 master and doctoral students per year.

2. Discipline of Introduction to Health Informatics, Nursing School, Undergraduate and graduate Program, Federal University of Sao Paulo, 186 students per year.

3. Specialization Program in Nursing Informatics, Federal University of Sao Paulo, 16 students per year.

4. Discipline of Health Informatics and Decision Support Systems, Graduate Program, Federal University of Sao Paulo, 8 doctoral and 5 master students from 1999 to 2002.

5. Discipline of Medical Informatics, Specialization Course, Catholic University of Rio de Janeiro, 35 postgraduate medical and engineering students per year.

\section{Conclusion}

In 1999, we started a bilateral collaboration for training medical informaticians. Participation from U.S. and Brazilian faculty began at the proposal phase, and continued until the final implementation phase. The faculty interactions during the course have already led to joint efforts in research and implementation of several courses, tailored to the local needs.

From our experience, it is essential that both sides communicate frequently and openly about their expectations and potential for contribution. It is also important to keep the consortium opened to multiple institutions. This aspect facilitated the interaction among Brazilian professionals and between Brazilian and US faculties to enhance efforts and to avoid duplication. In no single center in Brazil nor in the U.S. is it possible to find specialists in all subareas of health informatics. The strength of our program is to congregate such specialists in the pursuit of a common goal: provide state-of-the-art training for health informatics students regardless of the country in which the institutes are located.

The courses developed under this program are freely available. We encourage collaboration from other countries, and would like to increasingly interaction with faculty who have the same objectives. We believe that similar consortia may be formed among faculty from different countries. However, it is necessary to emphasize that the success of this bilateral collaboration for training of biomedical informaticians is completely dependent on the efforts of the faculty and students involved in the program. The faculty interactions during the course have already led to joint efforts in research [4] and implementation of several local courses, tailored to local needs. 
The training program was based on a combination of onsite and online instruction. The onsite instruction was targeted at faculty, who can use the online resources to complement their teaching materials. Our program is directed towards the enrichment of Brazilian faculty, because each one has the potential to train several students. Long-term training abroad would be logistically difficult, expensive, and less likely to be adapted to the Brazilian cultural and socio-economical reality. In our program, U.S. faculty interact with Brazilian peers and have an opportunity to understand the challenges of developing a program for specialized education in a developing country. Our program is focused on training the trainers in a collaborative fashion, preparing individuals to conduct researchand teaching without frontiers.

By the end of 2003 we found that around 1,724 people were involved in the program as a faculty or student in the program.
Related to the initiatives outside the objectives of the consortium, we understand that several other undergraduate and graduate courses are being developed and implemented in the country that we did not mentioned in this paper, for it was not our intention to cover all existing courses in the country.

\section{Acknowledgments}

This project was funded by grant 1D43TW01279-01 from the Fogarty International Center and the National Library of Medicine, National Institutes of Health. We thank all faculty for their commitment to this program, as well as Dr. Paulo M. Carvalho Jr. and Dr. Renan Moritz Varnier R Almeida for contributing with a summary of their department histories and activities.

\section{References}

1. Ohno-Machado L, Marin HF, Marques EP, Massad E, Greenes RA. Training in Medical Informatics: Combining Onsite and Online Instruction. MEDINFO 2001 .

2. Ohno-Machado L, Marin HF, Marques EP, Massad E, Greenes RA. Health Informatics Education: Onsite and Online Instruction Project - Preliminary Results. Proceedings of the First Brazilian Symposium on Mathematical and Computational Biology. E-PaperEd. Riode Janeiro, Brazil; 2001.

3. Marques EP, Marin HF, Massad E, Fraser H,Ohno-MachadoL.Educational Activities of the Brazil-USA Consortium for Health Informatics. Proceedings of the Second Brazilian Symposium on Mathematical and Computational Biology. E-Paper Ed. Rio de Janeiro, Brazil; 2002.

4. Ohno-Machado L, Lacson R, Massad E. Decisiontrees and fuzzy logic: Acomparison of models for the selection of measles vaccination strategies in Brazil. Proc AMIA Symp. 2000:625-9.

Address of first author:

Eduardo Pereira Marques, M.D., D.Sc.

State University of Rio de Janeiro

R Gen Urquiza 139

CEP 22431-040 - Rio de Janeiro

RJ - Brazil

E-mail: eduardo@marques.com 